\title{
Ética na Avaliação Psicológica: Velhas Questões, Novas Reflexões ${ }^{1}$
}

\author{
Monalisa Muniz ${ }^{1}$ \\ ${ }^{1}$ Universidade Federal de São Carlos, SP, Brasil.
}

\begin{abstract}
Resumo: $\mathrm{O}$ objetivo do artigo foi trazer reflexões adicionais à temática da ética na avaliação psicológica. $\mathrm{O}$ trabalho foi organizado em três principais discussões. A primeira aborda o quanto os documentos normativos, no contexto brasileiro, reafirmam o caráter dinâmico, transformador, cultural e benéfico de uma Psicologia e avaliação psicológica pautadas na ética. Na segunda parte, analisando artigos internacionais e nacionais, surgem dois pontos principais de reflexão: as mudanças na ética em avaliação psicológica provocadas por demandas sociais, e o quanto mais mudanças ainda são necessárias em razão de questões negligenciadas, que carecem de um maior cuidado pela avaliação psicológica. Num terceiro momento, discutiu-se a formação em avaliação psicológica, a partir de uma análise de processos éticos julgados pelo CRP-SP entre os anos de 2014 e 2018 (primeiro trimestre). Por fim, buscou-se argumentar sobre a necessidade de uma formação ética permanente, para além de uma formação estritamente profissional, a ocorrer nos mais variados espaços da sociedade, ao longo do desenvolvimento do ser humano, que estimule uma consciência social baseada na teoria e na práxis.
\end{abstract}

Palavras-chave: Psicologia, Formação, Código de Ética.

\section{Ethics in Psychological Assessment: Old Questions, New Reflections}

\begin{abstract}
The objective of this article was to bring further reflections to the matter of ethics in psychological assessment. The work was arranged in three main discussions. The first one deals with how regulatory documents, in the Brazilian context, reaffirm the dynamic, transformative, cultural and beneficial feature of psychology and psychological assessment based on ethics. In the second part, by having analyzed national and international articles, two main issues emerged. Firstly, the changes in ethics in psychological assessment caused by social demands and secondly, that many more changes are still needed due to neglected issues, which need a greater attention by psychological assessment. In the third part, training in psychological assessment was discussed taking account of ethical lawsuits judged by CRP-SP between 2014 and 2018 (first quarter). Finally, the need for a permanent ethical training extending beyond the strictly professional dimension and to take place in the most varied groups of society was under consideration, throughout a human development that stimulates a social consciousness based on theory and practice (praxis).
\end{abstract}

Keywords: Psychology, Training, Code of Ethics.

\footnotetext{
${ }^{1}$ Agradecimentos à equipe da Comissão de Ética do Conselho Regional de Psicologia de São Paulo (CRP-06), Dana Raíssa Rocha Martins, Denise Harumi Sakô, Luiza Figueiró Petry, Luciana Liberati Mantovani, Patrícia Gomes Ramalho, Philippe Benhayon, Rodrigo Toledo, em especial às já mencionadas Denise, Luciana e Patrícia. Ao Prof. Dr. Humberto Lourenção pela revisão do texto, em especial sobre a temática da ética.
} 


\title{
Ética en la Evaluación Psicológica: Viejas Cuestiones, Nuevas Reflexiones
}

\begin{abstract}
Resumen: El objetivo del artículo fue traer reflexiones adicionales a la temática de la ética en la evaluación psicológica. El trabajo se organizó en tres principales discusiones. La primera aborda cuánto los documentos normativos, en el contexto brasileño, reafirman el carácter dinámico, transformador, cultural ybenéfico de una psicología y evaluación psicológica pautadas en la ética. En la segunda parte, analizando artículos internacionales y nacionales, surgen dos puntos principales de reflexión: los cambios en la ética en evaluación psicológica provocados por demandas sociales, y cuanto más cambios todavía son necesarios en razón de cuestiones desatendidas, que carecen de un mayor cuidado por parte de la atención evaluación psicológica.. En un tercer momento se discutió la formación en evaluación psicológica, a partir de un análisis de procesos éticos juzgados por el CRP-SP entre los años 2014 y 2018 (primer trimestre). Por último, se buscó argumentar sobre la necesidad de una formación ética permanente, además de una formación estrictamente profesional, que debe ocurrir en los más variados espacios de la sociedad, a lo largo del desarrollo del ser humano, que estimule una conciencia social basada en la teoría y en la praxis.
\end{abstract}

Palabras clave: Psicología, Formación, Código de Ética.

\section{Introdução}

O tema da relação entre ética e avaliação psicológica tem sido protagonista em diversas publicações científicas no Brasil, inclusive recentes (Amêndola, 2014; Anache, \& Reppold, 2010; Frizzo, 2004; Hutz, 2002; 2009; 2015; Jesus Junior, Bighetti, Freitas, Oswaldo, \& Noronha, 2007; Pellini, \& Leme, 2011; Queiroz, Segabinazi, \& Borsa, 2016; Rodrigues, 2011; Wechsler, 2001; Zaia, Oliveira, \& Nakano, 2018). Dentro desse rol de publicações ainda se acrescentam os textos que foram gerados no Ano Temático da Avaliação Psicológica que teve como principal objetivo refletir sobre a interface dessa área com os aspectos éticos, técnicos e o respeito aos Direitos Humanos (Conselho Federal de Psicologia - CFP, 2011). Portanto, a finalidade do presente artigo é trazer reflexões adicionais sobre a temática, buscando contribuir com o avanço dos debates presentes nas inquietudes e propostas dos demais autores supracitados.

\section{Ética filosófica e profissional}

Em seu sentido etimológico, ética vem do idioma grego e designa a índole, no sentido de caráter e temperamento natural da pessoa (Pereira, s/d). Na filosofia, derivando de seu sentido etimológico, o termo ética passou a significar o estudo dos juízos de apreciação referentes à conduta humana suscetível de qualificação do ponto de vista do bem e do mal, seja relativamente a determinada sociedade, seja de modo absoluto. Em outras palavras, ética é o estudo sistemático da argumentação sobre como nós seres humanos devemos agir, sobre aquilo que é bom para o indivíduo e para a sociedade (Moore, 1975).

Ética é também a filosofia da moral, portanto, um pensamento reflexivo sobre os valores e as normas que regem as condutas humanas. Cada cultura, cada sociedade institui uma moral, uma conduta considerada correta, isto é, um conjunto de valores concernentes ao bem e ao mal, ao permitido e ao proibido, válido para todos os seus integrantes (Chauí, 1994). Dessa forma, ética pode ser definida como estudo do comportamento moral dos homens em sociedade; sendo a moral, portanto, objeto de estudo da ética (Nalini, 1997).

Na história da ética filosófica, David Hume, procurou analisar a controvérsia em torno dos fundamentos gerais da moral: se eles derivam da razão ou do sentimento, ou seja, se chegamos ao conhecimento deles por meio de uma sequência de argumentos e de induções ou por meio de um sentimento imediato e de um sutil sentido interno. Hume propôs uma definição que julgou solucionadora dessa controvérsia: o fundamento da moral é a utilidade. Em outros termos, a razão e sentimento constituem igualmente a moral; a razão nos instrui sobre as diversas direções da ação, a humanidade nos faz estabelecer a distinção em favor daquelas que são úteis e benéficas. Para Hume, o sentimento de humanidade, ou seja, a tendência a ter prazer pela felicidade do próximo, é o fundamento da moral, o móvel fundamental da conduta humana. Enfim, a moral inclina o homem a promover a felicidade dos seus semelhantes (Abbagnano, 1998). 
Partindo do princípio de que as sociedades existem para garantir a vida dos seres humanos, em que cada um tenha acesso a tudo que possa usufruir para seu pleno desenvolvimento, a função social da moral é exatamente ajudar a alcançar esse objetivo, norteando as relações entre os seres humanos entre si, na comunidade, e com a natureza. Tendo isto em mente, não é difícil visualizar que o enfrentamento dos grandes problemas que nos afligem como a fome mundial, os problemas ecológicos, o racismo, a xenofobia, a violência e a guerra, depende da participação de todos. Isto exige a constituição de princípios e valores aceitos e válidos para toda uma coletividade, no plano local e no plano global, fundamentados na ética da responsabilidade, em que padrões de conduta são definidos por cada grupo sociocultural em um movimento dinâmico, acompanhando as mudanças da realidade (Singer, 1998).

A consciência ética ocorre quando o sujeito percebe a diferença entre o que é e o que deveria ser, ou seja, é o estranhamento frente à realidade, o questionamento da moralidade vigente que determina a convivência social. O processo de libertação passa, portanto, por esta percepção (da diferença entre o ser e o dever-ser) e a vontade de construir um futuro social diferente e melhor do que o presente. Para esta construção as boas intenções não são suficientes; é preciso uma avaliação sobre os efeitos não intencionais das nossas ações. Assim, a consciência ética é muito mais que uma simples assimilação de valores e normas morais vigentes na sociedade; ela emerge com a desconfiança de que os valores morais da sociedade, internalizados no código moral de cada sujeito, podem encobrir interesses em prol de uma minoria, propalados por instituições de poder, e colocados acima do bem de uma coletividade maior (Singer, 1998).

Contendo esses mesmos aspectos da ética filosófica, tem-se a ética profissional que é uma reflexão sobre o conjunto de normas de conduta que devem ser postas em prática no exercício da profissão, resultando em um corpo normativo que regulamenta a profissão. A ética profissional aborda questões tão relevantes que ultrapassa o campo profissional em si. Questões como descriminalização do aborto, instituição da pena de morte, eutanásia, AIDS etc., por exemplo, são questões que exigem uma profunda reflexão ética e, um profissional, ao se debruçar sobre elas, não o faz apenas como tal, mas como um pensador, um filósofo da ciência, implicada na profissão que exerce.

\section{Ética na profissão da Psicologia e na atuação em avaliação psicológica}

A profissão do psicólogo, assim como as demais profissões, é pautada em um código de ética profissional, esteja ele expresso ou não em códigos oficiais, visando garantir que as relações entre os profissionais da área e destes com a sociedade ocorram envolvendo valores tais como o respeito, a justiça e a dignidade. O código de ética estabelece padrões para que o profissional possa refletir sobre sua prática, tornando-se consciente da sua responsabilidade, pessoal e coletiva, pelas consequências de suas ações no exercício profissional (Resolução No 010/2005). Possibilitando assim, que o psicólogo seja o filósofo da ciência denominada Psicologia, refletindo sobre quais ações são necessárias para a construção do bem do outro e da sociedade.

Os princípios e normas contidos nos códigos de ética pautam a conduta profissional em prol do respeito às pessoas e aos seus direitos fundamentais, tendo em vista a felicidade e a realização delas. A reflexão sobre a ética é algo constante, por isso um código de ética não deve ser compreendido como um conjunto de normas estáticas, ao contrário, as sociedades mudam, as profissões se transformam, o entendimento sobre o ser humano e seus direitos e deveres se modifica (Resolução $\left.\mathrm{N}^{\circ} 010 / 2005\right)$. Sendo assim, a compreensão sobre a ética dos comportamentos está condicionada no espaço e no tempo, ou seja, intimamente ligada à cultura de um determinado país ou localidade que, por sua vez, está em constante transformação, e por isso não há como se obter um código de ética profissional ou um documento normativo de conduta universal.

Tendo em vista que cada código de ética resulta de uma realidade sociocultural específica, no Brasil há o Código de Ética Profissional do Psicólogo, normatizado por meio de Resolução do CFP, a qual se apresenta em sua quarta edição (Resolução No 010/2005), sendo que o primeiro entrou em vigor em 1975 (Anache, \& Reppold, 2010). O atual código brasileiro tem suas especificidades quanto às condutas, construídas a partir de discussões com a categoria, com participação da sociedade. A opção por este processo democrático refletiu o Estado de Direito que o nosso país havia alcançado e que provocou a elaboração de um novo código condizente com novas demandas da categoria e sociedade (Resolução № 010/2005).

Como ilustração das mudanças advindas da historicidade do Código de Ética Profissional do Psicólogo brasileiro, destaca-se a patologização das crianças que 
fracassam nas escolas, a segregação de pessoas com transtornos mentais nos hospitais psiquiátricos e o uso de testes psicológicos sem evidências de validade, que foram permitidos há pouco tempo e que hoje são compreendidos como arbitrários e preconceituosos (Anache, \& Reppold, 2010). Essas modificações são consonantes com o caráter dinâmico e transformador da ética, propiciando o desenvolvimento benéfico das culturas expressas pelas pessoas e sociedades. Logo, a Psicologia como ciência e profissão, ao ser inerentemente ética, também se apropria dessas mesmas qualidades que impulsionam o desenvolvimento humano.

A atuação do psicólogo, incluindo sua prática na avaliação psicológica, deve respeitar os princípios fundamentais e as responsabilidades descritas no Código de Ética Profissional do Psicólogo. O atual código de ética (Resolução No 010/2005) é pautado em sete princípios fundamentais que são transversais nas condutas descritas como responsabilidades do psicólogo. Em síntese, os princípios orientam que a conduta ética do psicólogo seja baseada nos direitos humanos universais, ressaltando sua responsabilidade na construção da justiça social em diversos contextos e na dignidade da atuação profissional (Resolução $\mathrm{N}^{\circ}$ 010/2005, p. 07).

Além dos princípios, no Código vigente são elencadas 72 condutas que devem ser praticadas pelo psicólogo no exercício da profissão. Dessas, 10 são mais específicas à avaliação psicológica e aparecem nos artigos $1^{\circ}$ (são deveres fundamentais do psicólogo) e $2^{\circ}$ (ao psicólogo é vedado). Fazem parte do artigo $1^{\circ}$ : prestar serviço utilizando conhecimentos e técnicas reconhecidamente fundamentadas na ciência psicológica (alínea c); fornecer informações sobre o objetivo do trabalho que será realizado (alínea f); fornecer informações, a quem de direito, sobre os resultados de serviço psicológico prestado, transmitindo somente o que for necessário para tomada de decisão que afetem o usuário ou beneficiário (alínea g); e zelar pela guarda, empréstimo, comercialização, aquisição e doação de material privativo do psicólogo (alínea i). No artigo $2^{\circ}$ se destaca: emitir documento sem qualidade teórica, técnica e científica (alínea g); interferir na validade e fidedignidade de instrumentos e técnicas psicológicas, adulterar seus resultados ou fazer declarações falsas (alínea h); ser perito avaliador ou parecerista em situações que há vínculos pessoais ou profissionais (alínea k); realizar diagnósticos, divulgar procedimentos ou resultados que exponham pessoas, grupos ou organizações; preservar o sigilo das informações (alínea q). Por fim, o artigo 18: não divulgar, ensinar, ceder, emprestar ou vender a leigos instrumentos e técnicas psicológicas que permitam ou facilitem o exercício ilegal da profissão (Resolução $N^{\circ} 010 / 2005$ ).

Os princípios e condutas descritas acima, junto com as demais contidas no código, são bem explicitadas e organizadas, o que pode levar o leitor (incluindo psicólogos) a interpretar que as condutas são simples e fáceis de praticar no dia a dia da avaliação psicológica. No entanto, nem sempre tal interpretação é correta, dado que é comum na avaliação psicológica se deparar com situações que fazem o psicólogo refletir sobre sua prática em contraste com o que já está normatizado no Código.

Diante disso, não raro, o profissional psicólogo enfrenta situações nas quais não há uma conduta ética explícita de como deve agir, nem mesmo ao consultar o Código de Ética Profissional do Psicólogo, deparando-se, assim, com dilemas éticos. Um exemplo na avaliação psicológica é o uso ou não de testes projetivos em processos seletivos, uma vez que foram criados para auxiliar a prática clínica e são instrumentos que acessam conteúdos além dos necessários para o objetivo da situação (Hutz, 2009). Outra situação é sobre a avaliação psicológica para redesignação de sexo, refletir sobre o quanto realmente ela é necessária, o quanto pode ferir a autonomia da pessoa, como se ela fosse incapaz de decidir sobre sua vida e de suportar as consequências advindas dessa decisão.

Isso faz ponderar que, o fato da ética ser sempre pensada por humanos, a partir de suas crenças, experiências e percepções, os faz acreditarem, muitas vezes veementemente, que estão fazendo o bem, incluindo a crença de que o outro agradecerá o bem que está recebendo, no futuro se ainda não o percebeu. Ou seja, o fundamento da moral e da ética que, segundo Hume, é ter prazer ao ver o outro feliz pode ser ofendido, na medida em que se procura formatar o outro sob padrões e referências alheios ao seu ser.

É importante ressaltar que os Princípios Fundamentais do Código de Ética Profissional do Psicólogo (Resolução No 010/2005) são transversais e orientativos para que o psicólogo estabeleça relações com a sociedade, a profissão, as entidades e a ciência, possibilitando a necessária reflexão sobre a prática contextualizada com o social e o institucional. Ou seja, os princípios fundamentais não são as condutas em si, mas sim um conjunto de ideias norteadoras que perpassam as condutas, estejam elas descritas ou não no Código, pois uma das 
funções dos princípios é possibilitar a reflexão em todas as situações, práticas e relações.

No Brasil, o psicólogo, além do Código de Ética, precisa ter o conhecimento sobre as resoluções do CFP que normatizam algumas práticas e contextos específicos da avaliação psicológica (há para outras áreas, mas que não são objetos do presente artigo). Essas resoluções têm como base o Código de Ética Profissional do Psicólogo, mas abordam especificidades de determinados contextos nos quais há o uso da avaliação psicológica, como por exemplo a Resolução № 002/2016 sobre concursos públicos e processos seletivos.

Diversas resoluções já foram modificadas, revogadas ou atualizadas, o que demonstra o quanto o Sistema Conselhos (Conselho Federal e Regionais) está sensível às demandas da categoria e sociedade, reafirmando o caráter dinâmico, transformador, cultural e benéfico de uma Psicologia pautada na ética. Dentre essas resoluções, a $\mathrm{N}^{\circ} 009 / 2018$, perpassa e interfere em todas as demais relacionadas à avaliação psicológica, pois trata justamente de diretrizes básicas para a realização da avaliação psicológica, incluindo o uso de métodos, técnicas e instrumentos, embasados na justiça e proteção dos direitos humanos. Ainda, regulamenta sobre a avaliação para que um teste seja considerado psicológico e favorável para o uso dos profissionais psicólogos.

Ao vigorar a 009/2018, foram revogadas as Resoluções $\mathrm{N}^{\circ} 002 / 2003$ e $\mathrm{N}^{\circ} 005 / 2012$, as Notas Técnicas $\mathrm{n}^{\circ} 01 / 2017$ e $\mathrm{n}^{\circ} 02 / 2017$. É importante destacar que a Resolução № 002/2003 (aprimoramento da $\mathrm{N}^{\circ}$ 025/2001) é um marco histórico para a avaliação psicológica no Brasil ao que se refere a regulamentação do uso, da elaboração e da comercialização de testes psicológicos em nosso país. O principal resultado dessa ação foi o aumento significativo da qualidade dos testes psicológicos, estabelecendo que apenas podem ser utilizados aqueles que demonstram comprovações científicas favoráveis de evidências de validade, precisão e normatização. Esse movimento para a qualificação dos instrumentos propiciou que a Psicologia como ciência e os psicólogos praticantes desse conhecimento, oferecessem à sociedade uma atuação ética, garantindo o que está preconizado no Código de Ética Profissional do Psicólogo, mais especificamente no princípio fundamental IV - segundo o qual, o psicólogo atuará com responsabilidade, por meio do contínuo aprimoramento profissional, contribuindo para o desenvolvimento da Psicologia como campo científico de conhecimento e de prática - e no artigo $1^{\circ}$ dos deveres fundamentais do psicólogo, referente a prestar serviço utilizando conhecimentos e técnicas reconhecidamente fundamentadas na ciência psicológica.

\section{A discussão da ética na avaliação psicológica a partir dos debates presentes em artigos científicos}

As mudanças nos Código de Ética Profissional do Psicólogo no Brasil, e também em outros documentos que normatizam as condutas éticas, refletem as demandas da sociedade. Com o intuito de verificar o que recentemente está sendo debatido sobre o tema ética e avaliação psicológica, realizou-se um levantamento de artigos científicos, avaliados por pares, dentro da área da Psicologia, nos últimos cinco anos (2013-maio/2018) e utilizando os termos ("psychological assessment" OR "psychological evaluation") AND (ethics OR ethic OR ethical) na base de dados geral dos periódicos da Capes.

A busca resgatou 1.496 artigos, mas por meio da leitura dos resumos e palavras-chave, somente em 14 trabalhos foi identificado algum debate entre avaliação psicológica e ética. Desses, seis discutem sobre as novas tecnologias para avaliação e intervenção em Psicologia (Duncan, Velasquez, \& Nelson, 2014; Fromberger, Jordan, \& Müller, 2018; Luxton, 2014; Luxton, Pruitt, \& Osenbach, 2014; Mueller, \& Piper, 2014; Prentice, \& Dobson, 2014), dois sobre a importância de psicólogos serem treinados para realizar avaliação psicológica (Evans, \& Finn, 2016; Ready, \& Veague, 2014), um sobre candidatos a cirurgia bariátrica (Rouleau, Rash, \& Mothersill, 2016), um sobre coleta de dados com a população idosa (Diniz, \& Amado, 2014), um sobre avaliação em contextos multiculturais e com poucos recursos (Laher, \& Cockcroft, 2017), um sobre a população surda (Boness, 2016), um sobre dificuldades da atuação do psicólogo (Hazboun, \& Alchieri, 2014) e um sobre processos éticos julgados no CFP (Zaia, Oliveira, \& Nakano, 2018).

É importante ressaltar que dentre esses artigos, somente um (Rouleau et al., 2016) teve como principal objetivo a discussão sobre a ética na avaliação psicológica, mesmo assim, dentro de um contexto específico. O trabalho traz uma reflexão sobre as questões éticas envolvidas em avaliações psicossociais realizadas por profissionais da saúde, o que abrange também a avaliação psicológica e o psicólogo. Os autores pontuam que muito tem se discutido sobre as avaliações para esse contexto, mas a questão ética é muito pouco debatida. 
Os demais artigos mencionam brevemente a temática, mas o objetivo compreende outras atuações do psicólogo ou algum procedimento ou técnica específicas. No entanto, todas as temáticas tratadas nos artigos, dentre outras que não surgiram, como por exemplo, redesignação de sexo, avaliação de pessoas com outros tipos de deficiência e avaliação para portes de armas, são assuntos que fazem emergir muitas questões éticas dentro da avaliação psicológica, como por exemplo: há instrumentos e/ou técnicas psicológicas cientificamente comprovadas e adequadas para avaliar todas as populações? Até que ponto a avaliação psicológica deve interferir na tomada de decisão para a realização de cirurgia bariátrica ou redesignação de sexo? Quais são as condutas éticas a serem adotadas diante de situações e demandas não discutidas e orientadas na área da avaliação psicológica? O psicólogo tem uma formação que o capacite a realizar avaliações psicológicas?

Em geral, quando uma temática começa a se tornar muito evidente, com grande demanda da sociedade e da categoria de psicólogos, a tendência é ser publicada alguma orientação dos conselhos ou das associações da área profissional. Fazendo a interlocução entre demandas da sociedade e produção de normativas éticas o CFP aprovou e publicou no Diário Oficial da União a Resolução CFP Coordenação de Aperfeiçoamento de Pessoal de Nível Superior № 011/2018 que regulamenta a prestação de serviços psicológicos realizados por meios de tecnologias da informação e da comunicação e revoga a Resolução $\mathrm{N}^{\circ}$ 11/2012, que já permitia alguns serviços psicológicos nessa modalidade. A nova Resolução, de 2018, expandiu o rol desses serviços ofertados por meios tecnológicos. Essa resolução não é específica para avaliação psicológica, mas contribui em muito para repensar suas questões éticas a partir da atual e contínua revolução tecnológica, corroborando com a reflexão sobre a temática mais encontrada no levantamento de artigos feito para o presente trabalho e que discutem a aplicação das novas tecnologias para a área da Psicologia e avaliação psicológica.

A Resolução $N^{\circ} 011 / 2018$ permite a prestação de serviços psicológicos, entre eles a avaliação psicológica, incluindo os testes psicológicos, por meios tecnológicos de informação e comunicação. Muitos são os pontos favoráveis dessa nova forma de atuação do psicólogo, como por exemplo, possibilitar atendimento a pessoas ou grupos que, por alguma razão, não conseguem se deslocar até o local de atendimento. No entanto, apesar de essa resolução cuidar para regulamentar e orientar a melhor conduta desse meio de serviço, como a obrigação do psicólogo em garantir o sigilo das informações, ter o cadastro atualizado anualmente no Conselho, entre outros, ainda há questionamentos. Por exemplo, esse tipo de serviço resulta em precarização e/ou banalização das práticas psicológicas, dificultando até mesmo o estabelecimento do vínculo entre cliente e psicólogo, comprometendo o acolhimento, que é essencial para qualquer prática da Psicologia? Em específico para a avaliação psicológica, há prejuízos na técnica da observação, tão presente no processo, restringindo uma análise mais apurada?

Dos artigos resgatados no levantamento, apenas dois abordam o contexto brasileiro (Zaia et al., 2018; Hazboun, \& Alchieri, 2014), o primeiro discorre sobre os processos éticos julgados pelo CFP, e o segundo sobre as dificuldades para atuar na avaliação psicológica. Diante de tão poucas ocorrências, com o objetivo de levantar artigos brasileiros sobre a temática, fez-se uma pesquisa de levantamento, também na base geral do periódico Capes, utilizando os termos ética e avaliação psicológica conjuntamente, com critério para aparecer somente artigos revisados por pares e sem restrição de data (mesmo assim surgiram artigos somente a partir de 2007), retornou 188 trabalhos, mas somente seis pesquisas debateram a temática em questão, incluindo a de Zaia et al. (2018).

Somando-se aos dois trabalhos supracitados (Zaia et al., 2018; Hazboun, \& Alchieri, 2014), cinco novos foram coletados, desses somente dois analisaram a ética na avaliação psicológica como objetivo principal (Rodrigues, 2011; Jesus Junior et al., 2007), os outros abordaram a temática brevemente, pois os assuntos principais foram: avaliação psicológica para porte de armas (Rafalski, \& Andrade, 2015), formação em Psicologia (Amêndola, 2014), conteúdos e metodologia de ensino em avaliação psicológica (Noronha, Castro, Ottati, Barros, Santana, 2013) e estrutura interna de um questionário para verificar a competência em avaliação psicológica (Rueda, Noronha, Raad, Varandas, 2009).

Dos trabalhos que trataram especificamente da ética na avaliação psicológica, o primeiro (Jesus Junior et al., 2007) buscou verificar a percepção de alunos que cursavam Psicologia, e estavam matriculados nos anos iniciais $\left(1^{\circ}\right.$ e $\left.2^{\circ}\right)$ e final $\left(5^{\circ}\right)$, em relação aos fatores éticos envolvidos no processo da ava- 
liação psicológica. Para isso foi aplicada uma escala contendo sentenças com infrações éticas e os alunos deveriam, em uma escala de 0 a 3 , assinalar o quanto cada conduta indicava ou não uma falta ética. Os resultados apontaram que os alunos do último ano obtiveram desempenho menor do que os de anos iniciais, levando os autores a discutirem sobre a formação, o quanto o ensino sobre ética ao longo dos anos de estudo parece não agregar um maior conhecimento da prática em avaliação psicológica pautada na ética. O segundo artigo, baseado em pesquisa teórica (Rodrigues, 2011), enfatizou o uso ético dos testes psicológicos. A autora traz diretrizes sobre ética na avaliação psicológica, repercutindo sobre a utilização dos instrumentos psicológicos; também aborda a importância da formação em avaliação psicológica.

A partir dos artigos elencados na pesquisa de levantamento, dois pontos podem ser considerados para uma reflexão ética na área de avaliação psicológica. O primeiro, já comentado aqui, é o quanto de mudanças ocorrem na atuação ética em avaliação psicológica a partir de novas demandas da sociedade. Observa-se nos trabalhos citados uma diversidade de contextos, populações e formas de atuação que culminam na necessidade de repensar, mudar e criar novas condutas éticas para a prática da avaliação psicológica, como foi o caso das novas Resoluções do CFP, a № 009/2018 (avaliação psicológica e testes) e a № 011/2018 (serviços psicológicos por meio da tecnologia da informação e comunicação).

Devido ao fato de o mundo estar passando por uma revolução tecnológica, é compreensível e até aceitável que somente mais recentemente, como é o caso do que tem ocorrido no Brasil, estejam surgindo mudanças nas orientações de condutas éticas no que se referem ao uso de novas tecnologias. No entanto, questões bem anteriores, como o cuidar de pessoas com acesso restrito a recursos, $o$ atendimento a pessoas com deficiências e a pacientes bariátricos, a redesignação de sexo, entre outras, não têm sido suficientemente abordadas e, tampouco, diretrizes têm sido efetivadas para que a avaliação psicológica seja realizada de forma mais ética nestes contextos; não só no sentido reativo, mas focado no sentido proativo, que produza benefícios reais para essas populações.

O outro ponto é a importância de uma melhor formação em avaliação psicológica para o desenvolvimento de competências que garantam uma atuação ética nesta área. Esse questionamento surge a partir da complexidade da avaliação psicológica e da necessidade de novos conhecimentos para responder às novas demandas dessa área. Em específico três artigos do levantamento trazem essa reflexão (Evans, \& Finn, 2016; Jesus Junior et al., 2007; Ready, \& Veague, 2014). No Brasil, a formação em avaliação psicológica é temática constante, o que pode ser identificado, por exemplo, em várias referências citadas nesse texto e que abordam de forma principal ou secundária (se assim podemos dizer, já que a ética, por mais que não esteja explicitamente descrita, é inerente à prática) a temática da ética na avaliação psicológica (Amêndola, 2014; Anache, \& Reppold, 2010; Frizzo, 2004; Hazboun, \& Alchieri, 2014; Hutz, 2002; 2009; 2015; Jesus Junior et al., 2007; Noronha et al., 2013; Pellini, \& Leme, 2011; Queiroz et al., 2016; Rafalski, \& Andrade, 2015; Rodrigues, 2011; Wechsler, 2001; Zaia et al., 2018).

Em todas essas publicações o argumento que prevalece para explicar as eventuais infrações éticas cometidas na avaliação psicológica é o da formação insuficiente, que não possibilita desenvolver as competências necessárias para o psicólogo praticar avaliação psicológica; consequentemente haveria maior chance de se cometer infrações éticas. Expressando essa percepção, há três artigos que, ao levantar os processos éticos recebidos e julgados por Conselhos Regionais e Federal, nos quais a maioria ou muitos estão relacionados à avaliação psicológica, mencionam a importância da formação em avaliação psicológica como variável para diminuição das infrações éticas (Anache, \& Reppold, 2010; Frizzo, 2004; Zaia et al., 2018).

\section{Infrações éticas em avaliação psicológica: refletindo sobre a formação}

O trabalho de Frizzo (2004) teve como objetivo caracterizar infrações éticas cometidas por psicólogos inscritos no Conselho Regional de Psicologia do Estado do Paraná (CRP/08) entre os anos de 1992 e 2003. O levantamento foi feito sobre as denúncias efetivadas, antes de serem julgadas, ou seja, sobre infrações éticas supostamente cometidas, mas que se faz importante a análise, pois possibilita identificar que tipo de prática tende a ser denunciada e que poderá ou não ser penalizada ao final do processo.

Nos 39 processos analisados, foram identificadas 64 infrações supostamente cometidas, dessas, 18 $(46,15 \%)$ pertencem a categoria "falhas na realização de perícia/avaliação psicológica" e quatro $(10,25 \%)$ classificadas em "falhas na realização de psicotéc- 
nico/emissão de CNH”. A prática mais observada para essas classificações está relacionada às falhas técnicas no processo de avaliação psicológica/perícia, envolvendo procedimentos, utilização de testes, resposta aos quesitos, competência técnica e interferência nos resultados. Na discussão dos dados a autora questiona a formação nos cursos de graduação em Psicologia e a ética dentro dessa formação.

Anache e Reppold (2010) verificaram as infrações cometidas em 66 processos éticos julgados no CFP (os processos julgados nos CRP's cabem recurso ao CFP), no período de 2006 a 2008. Como o levantamento se ateve às ementas dos processos, foi possível resgatar somente quais artigos do Código de Ética Profissional do Psicólogo foram infringidos, sem a certeza de que estavam relacionados à avaliação psicológica e/ou teste psicológico. As condutas citadas pelas autoras que podem abranger a avaliação psicológica de forma mais direta se referem a fornecer, informar e orientar a quem de direito sobre os serviços prestados, os resultados decorrentes do trabalho e os encaminhamentos (Artigo 1, respectivamente as alíneas $\mathrm{f}, \mathrm{g}$ e h). Ainda, infrações que dizem respeito a emissão de documentos sem qualidade e fundamentação técnico-científica (Artigo 2, alínea g), interferência nas propriedades psicométricas dos instrumentos, adulteração de resultados e declarações falsas (Artigo 2, alínea h), e divulgação, ensino, empréstimo e venda a leigos de instrumentos e técnicas psicológicas (Artigo 18). Na conclusão as autoras também citam a questão da formação em avaliação psicológica como ponto fundamental para a atuação ética.

Por fim, o artigo de Zaia et al. (2018) traz uma análise dos processos que foram publicados na seção "Processos Éticos" do Jornal do Federal (publicação do CFP) entre os anos de 2004 e 2016. Ao total foram constatadas 286 infrações ao Código de Ética Profissional do Psicólogo em 26 edições do jornal. No entanto, somente nas três últimas edições $(110,111$ e 112) do período investigado houve melhor elucidação dos conteúdos das ementas, possibilitando identificar que dos 57 processos éticos que fazem parte dessas últimas edições, 35 (61,4\%) estão relacionados a área da avaliação psicológica. Desses 35, a prática mais infringida pelo psicólogo foi o laudo psicológico (citada 27 vezes), mas também apareceram menções sobre avaliação da Carteira Nacional de Habilitação - CNH (2), concurso público (1), falsificação de documentos (1), facilitação de aplicação de testes por não psicólogos (1), e irregularidades de modo geral (4). Nas discussões ressaltou-se o protagonismo da formação em avaliação psicológica, ou seja, a necessidade de uma formação continuada, incluindo graduação, especialização e pós stricto sensu, para que os psicólogos sejam capacitados para realizar avaliações com ética e qualidade técnica.

Com o objetivo de contribuir com mais elementos sobre a prática dos psicólogos e as infrações éticas cometidas no processo de avaliação psicológica, para o presente estudo foi realizado um levantamento dos processos éticos julgados pelo CRP-SP entre os anos de 2014 e 2018 (primeiro trimestre) que dizem respeito a área da avaliação psicológica. $\mathrm{O}$ acesso aos dados foi obtido a partir de uma solicitação à equipe da Comissão de Ética (COE) do CRP-SP. A equipe compilou os dados brutos a partir do Sistema Implanta-Módulo Processos (sistema informatizado, interno e sigiloso utilizado para a organização dos trabalhos da COE) e de arquivos manuais da COE, e posteriormente os organizou em uma planilha Excel. Para a análise dos dados a autora do presente artigo utilizou o Statistical Package for Social Science (SPSS), versão 21.

Foram analisados 45 processos éticos julgados no CRP-SP e destes, em um havia duas pessoas processadas. As categorias (sistematizadas pela equipe da $\mathrm{COE}$ e mantidas no presente artigo) elencadas para análise foram: ano, tema instaurado, subtema instaurado, local de atuação e andamento dos processos (julgamento). A Tabela 1 mostra o total de processos julgados por ano (2014 a 2018/primeiro trimestre), a quantidade e frequência dos relacionados à avaliação psicológica.

Como pode ser observado por meio da Tabela 1, os anos de 2015 e 2016 concentraram maior porcentagem de processos éticos julgados relacionados à avaliação psicológica. Para o ano de 2018 não foi possível analisar a porcentagem por dois motivos: os dados gerais ainda não estão disponíveis para consulta, e a quantidade obtida (um) se refere ao primeiro trimestre. No entanto, caso a quantidade ocorrida no primeiro trimestre seja semelhante para os demais, será observado novamente uma porcentagem equivalente a 2017.

Tabela 1

Processos julgados no CRP-SP no período de 2014 a 2018.

\begin{tabular}{lccccc}
\hline Área & 2014 & 2015 & 2016 & 2017 & 2018 \\
\hline Geral & 46 & 38 & 20 & 27 & INC* $^{*}$ \\
\multirow{2}{*}{ Aval Psi } & 13 & 17 & 11 & 3 & 1 \\
& $(28,27 \%)$ & $(44,74 \%)$ & $(55 \%)$ & $(11 \%)$ & 1 \\
\hline
\end{tabular}

*Informação ainda não disponível 
O dado de 2017 apresenta-se positivo, indicando uma redução significativa de processos éticos julgados. No entanto, é importante ressaltar que as informações são referentes a processos julgados, e há que se considerar os que ainda estão em análise, tramitando no CRP-SP. Por isso é preciso observar que não há uma correlação entre a quantidade de infrações cometidas e/ou denunciadas ao CRP-SP e o número de processos julgados no mesmo ano, pois este último depende do ritmo de trabalho das comissões julgadoras do CRP. Mesmo assim, pode-se considerar um dado animador e que deve ser acompanhado nos próximos anos para verificar sua confirmação. Esse dado não corrobora (e espera-se que dados futuros continuem a não corroborar) com os resultados das pesquisas realizadas por Frizzo (2004) e Zaia et al. (2018). Esses trabalhos não investigaram especificamente processos julgados no CRP-SP, mas nessas pesquisas observa-se que os dados tendem a apontar para um cenário mais negativo sobre as condutas éticas na prática da avaliação psicológica.

Sobre as decisões nos julgamentos há duas possibilidades: penalidade e arquivamento. Das penalidades aplicadas aos psicólogos envolvidos nos processos éticos, cabe mencionar que há cinco tipos: advertência, multa, censura pública, suspensão do exercício profissional, por até 30 dias, e cassação do exercício profissional. Essas duas últimas são ad referendum do CFP, mas em todas as penalidades cabe recurso ao CFP (Resolução $N^{\circ} 006 / 2007$ ). No entanto, há situações que se opte pelo Arquivamento, ou seja, quando se conclui que não há materialidade. Na Tabela 2 podem ser visualizadas a quantidade de penalidades e de arquivamento atribuídas no período de 2014 a 2018.

Como pode ser observado, a grande maioria dos julgamentos culminou em advertência. $\mathrm{O}$ artigo de Zaia et al. (2018), sem distinguir áreas, constatou que o arquivamento representou $30,07 \%$ das decisões dos CRPs, seguido da advertência $(26,57 \%)$ e censura pública $(19,58 \%)$. Esses dados, junto com

\section{Tabela 2}

Andamento dos processos - Julgamentos (penalidade e arquivamento).

\begin{tabular}{lcc}
\hline Julgamento & $f$ & $\%$ \\
\hline Advertência & 34 & 75,55 \\
Censura pública & 6 & 13,33 \\
Arquivamento & 5 & 11,11 \\
\hline
\end{tabular}

Fonte: Autoria do autor as informações contidas na Tabela 2, tendem a indicar uma direção mais orientativa dos Conselhos do que punitiva, pois as advertências são realizadas somente com a parte envolvida, dentro da sede ou subsede do Conselho ao qual o psicólogo está inscrito. A advertência, apesar de ser o momento da aplicação da pena, também é para orientar o psicólogo quanto à infração por ele cometida e reafirmar a importância da prática baseada nos princípios do Código de Ética do Psicólogo.

Dessa forma, dos 45 processos julgados, cinco foram arquivados, no entanto as análises seguintes foram realizadas considerando todos os processos julgados, pois mesmo que alguns processos tenham sido arquivados, não necessariamente não houve a infração ética. Como mencionado anteriormente, o arquivamento ocorre quando não há materialidade. Além disso, é importante ressaltar que ao chegar na etapa do julgamento o processo passou por diversas fases, que permitiram ao psicólogo sua ampla defesa. Entre as etapas, há momentos em que o processo poderia já ter sido arquivado, mas foi compreendido que, em tese, havia uma infração, então prosseguiu e culminou em julgamento. Na Tabela 3 podem ser visualizados os temas (contextos da avaliação psicológica) nos quais os processos julgados foram elencados.

Na Tabela 3 constata-se que no período estudado a maioria dos processos éticos (55,56\%) relacionou-se ao tema da Vara da Família. Entretanto, todos os temas elencados sugerem sobre a importância da avaliação psicológica como suporte à tomada de decisões que impactam nas vidas de pessoas.

A Tabela 4 se refere ao local de atuação dos psicólogos processados onde ocorreram as infrações. Nela se observa uma maior ocorrência de denúncia de infrações em consultório particular, que, no Brasil, é o local de maior atuação do psicólogo.

Tabela 3

Temas dos processos éticos julgados.

\begin{tabular}{lcc}
\hline Temas & $f$ & $\%$ \\
\hline Carteira Nacional de Habilitação & 8 & 17,78 \\
Vara da Infância e Juventude & 3 & 6,67 \\
Vara da Família & 25 & 55,56 \\
Vara Criminal & 4 & 8,89 \\
Porte de Armas & 3 & 6,67 \\
Concursos & 2 & 4,44 \\
\hline
\end{tabular}

Fonte: Autoria do autor 
Outro dado considerado se refere às práticas de atuação do psicólogo nas quais houve a denúncia à infração ética (categoria inicial denominada de subtema instaurado). Dentro dos 45 processos analisados entre 2014 e 2018, foi constatado o total de 95 práticas indicativas de supostas (posteriormente a grande maioria foi penalizada) infrações ao Código de Ética Profissional do Psicólogo (Tabela 5).

Por meio da Tabela 5 identifica-se que aproximadamente $72 \%$ das práticas julgadas nos processos éticos estão relacionadas a produção de documento e manejo da avaliação. $\mathrm{O}$ resultado referente a produção de documento corrobora com os resultados encontrados por Zaia et al. (2018) os quais apontam que a prática mais infringida pelo psicólogo foi o laudo psicológico.

A produção de documentos escritos advindos da avaliação psicológica é pautada na Resolução $\mathrm{N}^{\circ}$ 007/2003, que institui o Manual de Elaboração de Documentos Escritos produzidos pelo psicólogo que orienta a estrutura e o conteúdo dos documentos. Em especial, os laudos psicológicos, correspondem ao processo de avaliação realizado, no qual as análises contidas precisam ser fundamentadas de forma técnica, científica e ética. No entanto, há uma parte muito técnica e estrutural que quando violada já confere infração ética, por exemplo, o documento não conter todos os tópicos da estrutura mencionada no Manual. Esse dado também faz questionar a necessidade da Resolução $N^{\circ}$ 007/2003 ser aprimorada e atualizada, melhorando as informações contidas e adequando para novos tipos de documentos, por exemplo, o laudo pericial na avaliação forense.

Quanto ao manejo da avaliação psicológica, questões sobre a falta de fundamentação ou habilidade na condução do processo de avaliação psicológica se sobressaem. Isto pode ser relacionado aos dados do trabalho de Frizzo (2004) no qual a maioria das infrações, em tese, cometidas estava relacionada com falhas na realização de perícia/avaliação psicológica abrangendo técnicas, procedimento, testes, competência e interferência nos resultados. Por meio dos dados mostrados em todos os itens elencado na Tabela 5, observa-se a necessidade do desenvolvimento de competências para a realização da avaliação psicológica.

A partir da variedade e especificidades de contextos, temáticas e populações nos quais a avaliação psicológica atua, questiona-se como minimizar as infrações éticas cometidas nessa prática. A resposta é a mesma que foi apresentada e discutida em textos citados anteriormente (Amêndola, 2014; Anache, \& Reppold, 2010; Frizzo, 2004; Hazboun \& Alchieri, 2014; Hutz, 2002; 2009; 2015; Jesus Junior et al., 2007; Noronha et al.,

\section{Tabela 4}

Locais de atuação dos psicólogos que responderam aos processos éticos.

\begin{tabular}{lcc}
\hline Locais & $f$ & $\%$ \\
\hline Consultório & 23 & 51,11 \\
Trânsito ou Detran & 7 & 15,55 \\
Clínica & 5 & 11,11 \\
Fórum & 3 & 6,66 \\
Porte de Armas* & 2 & 4,44 \\
Centro de Convivência & 1 & 2,22 \\
ONG & 1 & 2,22 \\
Escola de Vigilantes & 1 & 2,22 \\
Crami & 1 & 2,22 \\
Sistema Prisional & 1 & 2,22 \\
\hline
\end{tabular}

Detran: Departamento Estadual de Trânsito; ONG: organização não governamental; Crami: Centro Regional de Atenção aos Maus Tratos;

*Porte de Armas: também pode ser elencada em consultório ou clínica, mas foi mantida a classificação elaborada pela COE.

Fonte: Autoria do autor

Tabela 5

Subtema instaurado - Práticas julgadas sobre a ocorrência de infração ética.

\begin{tabular}{lcc}
\hline Práticas Infringidas & $f$ & $\%$ \\
\hline Produção de documentos & 38 & 40,00 \\
Manejo & 30 & 31,60 \\
Teste psicológico & 10 & 10,53 \\
Devolutiva & 6 & 6,32 \\
Quebra de sigilo & 5 & 5,30 \\
Envolvimento Amoroso/Pessoal & 1 & 1,11 \\
Envolvimento Religioso & 1 & 1,11 \\
Prontuário/Registro de & 1 & 1,11 \\
Documento & 1 & 1,11 \\
Encaminhamento & 1 & 1,11 \\
Equipe de psicólogos/ & 1 & 1,11 \\
multidisciplinar & 1 & \\
Preconceito/Discriminação & &
\end{tabular}

Fonte: Autoria do autor 
2013; Pellini, \& Leme, 2011; Queiroz et al., 2016; Rafalski, \& Andrade, 2015; Rodrigues, 2011; Wechsler, 2001; Zaia et al., 2018), ou seja, uma formação qualificada em avaliação psicológica.

No entanto, para além da formação em avaliação psicológica, há a necessidade de uma formação ética consistente e permanente. Dentro da proposta de competências para a realização da avaliação psicológica (Nunes et al., 2012), a ética foi especificamente contemplada na competência "Considerar os aspectos éticos na realização da avaliação psicológica”, a qual pontua que a atuação deve se fundamentar nos preceitos éticos do Código de Ética Profissional do Psicólogo, e, para além disso, o psicólogo precisa ser ético de forma consciente, incorporando a dimensão ética que visa a construção de relações sociais humanizadas (Muniz, 2017).

Uma formação ética que estimula a consciência social, baseada na teoria e na práxis, contribuirá para o desenvolvimento de um sujeito mais atento às demandas dos extratos mais vulneráveis da sociedade, mais cuidadoso nas relações de microfísica de poder que estabelece em seu cotidiano, mais crítico em busca de princípios fundamentais de direito, dever, justiça, igualdade, liberdade, solidariedade e respeito para todos e entre todos. Um sujeito mais sensível, social e politicamente, terá maior probabilidade de agir eticamente em diferentes contextos de sua vida, particularmente, em seu trabalho.

Na ausência dessa consciência social, um código de ética profissional ou qualquer documento que orienta e/ ou normatize condutas éticas, tenderá a ter meramente um caráter policialesco, judicializante e punitivo. Apoiar e agir para que as pessoas nos mais variados contextos possam desfrutar, durante todo o seu desenvolvimento, de uma formação ética permanente, seja na escola ou em outras instituições, como na família, nos movimentos sociais, na convivência comunitária, estimulará com que se tenha cidadãos eticamente conscientes e atuantes, que estarão presentes em todas as profissões, incluindo a Psicologia e desenvolvendo o trabalho da avaliação psicológica. Nesse cenário, os códigos de éticas serviriam somente como registros formais dos valores e princípios que os membros de uma comunidade já vivenciam no dia-a-dia, ajudando na orientação e na própria formação ética.

\section{Considerações finais}

O presente artigo teve como objetivo trazer novos dados e reflexões que contribuam para o campo da discussão da ética na avaliação psicológica. Como pode ser observado ao longo do deste trabalho, muitos são os autores que discutiram amplamente ou de maneira mais sucinta sobre essa relação entre ética e avaliação psicológica. Por meio das informações aqui contidas, percebe-se um avanço, em nosso país, nessa temática, pois há que se reconhecer o esforço de se pensar uma avaliação psicológica pautada na ética, advindo de diferentes trabalhos e autores, bem como a qualidade das resoluções do CFP, apesar de utopicamente, se desejar que um dia não mais precisemos de regulamentações éticas.

Ainda há muito e sempre haverá o que ser melhorado nessa intersecção ética e avaliação psicológica, mas justamente pelo próprio caráter dinâmico dessas áreas que tendem a evoluir à medida que se deparam com novas demandas dos sujeitos e das sociedades. Lembrando, que os psicólogos devem ser protagonistas em produzir as transformações necessárias para que cada vez mais a avaliação psicológica promova $o$ bem de todos, em uma sociedade solidária. Assim, há de se reafirmar a importância de uma educação ética para todos, o que culminará em uma maior quantidade de pessoas/psicólogos como atores das mudanças necessárias, respondendo às demandas da sociedade de forma eficaz e consciente.

\section{Referências}

Abbagnano, N. (1998). Dicionário de filosofia. (21a ed.). São Paulo, SP: Martins Fontes.

Amêndola, M. F. (2014). Formação em psicologia, demandas sociais, contemporâneas e ética: Uma perspectiva. Psicologia: Ciência e Profissão, 34(4), 971-983. http://dx.doi.org/10.1590/1982 - 370001762013

Anache, A. A., \& Reppold, C. T. (2010). Avaliação psicológica: Implicações éticas. In A. A. Santos, A. A. Anache, A. E. Villemor-Amaral, B. S. V.Welang, C. T. Reppold, C. H. S. Nunes et al. (Orgs.), Avaliação psicológica: Diretrizes para a regulamentação da profissão (pp. 57-86). Brasília, DF: Conselho Federal de Psicologia.

Boness, C. L. (2016). Treatment of deaf clients: Ethical considerations for professionals in psychology. Ethics \& Behavior, 26(7), 562-585. https://doi.org/10.1080/10508422.2015.1084929 
Chauí, M. (1994). Convite à filosofia. São Paulo, SP: Ática.

Conselho Federal de Psicologia - CFP. (2011). Ano da avaliação psicológica: Textos geradores. Brasília, DF: o autor.

Diniz, A. M., \& Amado, N. (2014). Procedures for successful data collection through psychological tests in the elderly. Psicologia Reflexão e Crítica, 27(3), 491-497. https://doi.org/10.1590/1678-7153.201427309

Duncan, A. B., Velasquez, S. E., \& Nelson, E. (2014). Using videoconferencing to provide psychological services to rural children and adolescents: a review and case example. Journal of Clinical Child \& Adolescent Psychology, 43(1), 115-127. https://doi.org/10.1080/15374416.2013.836452

Evans, F. B, \& Finn, S. E. (2016). Training and consultation in psychological assessment with professional psychologists: suggestions for enhancing the profession and individual practices. Journal of Personality Assessment, 99(2), 175-185. https://doi.org/10.1080/00223891.2016.1187156

Frizzo, N. P. (2004). Infrações éticas, formação e exercício profissional em Psicologia (Dissertação). Universidade Federal de Santa Catarina, Florianópolis, SC.

Fromberger, P., Jordan, K., \& Müller, J. L. (2018). Virtual reality applications for diagnosis, risk assessment and therapy of child abusers. Behavioral Science \& the Law, 36(2), 235-244. https://doi.org/10.1002/bsl.2332

Hazboun, A. M., \& Alchieri, J. C. (2014). Dificuldades em avaliação psicológica segundo psicólogos brasileiros. Psico, 45(1), 83-89.

Hutz, C. S. (2009). Ética na avaliação psicológica. In C. S. Hutz (Org.), Avanços e polêmicas em avaliação psicológica (pp. 297-310). São Paulo, SP: Casa do Psicólogo.

Hutz, C. S. (2015). Questões éticas na avaliação psicológica. In C. S. Hutz, D. R. Bandeira, \& C. M. Trentini (Orgs.), Psicometria (pp. 165-174). Porto Alegre, RS: Artmed.

Hutz, C. S. (2002). Responsabilidade ética, social e política da avaliação psicológica. Avaliação Psicológica, 1(2), vii-ix. Recuperado de http://pepsic.bvsalud.org/scielo.php?script=sci_arttext\&pid=S167704712002000200001\&lng=pt\&tlng=pt.

Jesus Junior, A. G., Bighetti, C. A., Freitas, F. A., Oswaldo, Y. C., \& Noronha, A. P. P. (2007). Avaliação psicológica e ética: um estudo com universitários. Universitas: Ciência e Saúde, 5(1/2), 61-74. https://doi.org/10.5102/UCS.V5I1.267

Laher, S., \& Cockcroft, K. (2017). Moving from culturally biased to culturally responsive assessment practices in low-resource, multicultural settings. Professional Psychology: Research and Practice, 48(2), 115-121. http:/ /dx.doi. org/10.1037/pro0000102

Luxton, D. D. (2014). Artificial intelligence in psychological practice: current and future applications and implications. Professional Psychology: Research and Practice, 45(5), 332-339. http://dx.doi.org/10.1037/a0034559

Luxton, D. D., Pruitt, L. D., \& Osenbach, J.E. (2014). Best practices for remote psychological assessment via telehealth technologies. Professional Psychology: Research and Practice, 45(1), 27-35. https://doi.org/10.1037/a00344547

Moore, G. (1975). Princípios éticos. São Paulo, SP: Abril Cultural.

Mueller, S. T., \& Piper, B. J. (2014). The psychology experiment building language (PEBL) and PEBL test battery. Journal of Neuroscience Methods, 222, 250-259. http://dx.doi.org/10.1016/j.jneumeth.2013.10.024

Muniz, M. (2017). Competências e cuidados para a administração da avaliação psicológica e dos testes psicológicos. In M. R. C. Lins, \& J. C. Borsa (Org.), Avaliação psicológica: Aspectos teóricos e práticos (pp. 100-114). Petrópolis, RJ:Vozes.

Nalini, J. R. (1997). Ética geral e profissional. São Paulo, SP: Revista dos Tribunais.

Noronha, A. P. P., Castro, N. R., Ottati, F., Barros, M.V.C., \& Santana, P. R. (2013). Conteúdos e metodologias de ensino de avaliação psicológica: um estudo com professores. Paidéia, 23(54), 129-139. http://dx.doi.org/10.1590/198243272354201315

Nota técnica $N^{o} 001 / 2017$, de 5 de maio de 2017. Altera a Nota Técnica no $02 / 2016$, que orienta psicólogos, editoras e laboratórios responsáveis pela utilização e comercialização de serviços, recursos e produtos psicológicos em ambiente virtual, em plataformas informatizadas. Brasília, DF: Conselho Federal de Psilcologia.

Nota técnica No 002/2017, de 5 de maio de 2017. Orientar sobre atualização das normas de testes psicológicos. Brasília, DF: Conselho Federal de Psilcologia.

Nunes, M. F. O., Muniz, M., Reppold, C. T., Faiad, C., Bueno, J. M. H., \& Noronha, A. P. P. (2012). Diretrizes para o ensino de avaliação psicológica, Avaliação Psicológica, 11(2), 309-316. 
Pellini, M. C. B. M., \& Leme, I. F. A. S. (2011). A ética no uso de testes no processo de avaliação psicológica. In R. A. M. Ambiel, I. S. Rabelo, S. V. Pacanaro, G. A. S. Alves, \& I. F. A. S. Leme (Orgs). Avaliação psicológica: Guia de consulta para estudantes e profissionais de psicologia (pp. 163-180). São Paulo, SP: Caso do Psicólogo.

Pereira, I. (s/d). Dicionário grego-português, português-grego (7a ed.). Braga: Apostolado da Imprensa.

Prentice, J. L., \& Dobson, K. S. (2014). A review of the risks and benefits associated With mobile phone applications for psychological interventions. Canadian Psychology, 55(4), 282-290. http://dx.doi.org/10.1037/a0038113

Queiroz, F, Segabinazi, J. D., \& Borsa, J. C. (2016). Aspectos éticos na avaliação psicológica. In M. R. C. Lins, \& J. C. Borsa (Orgs.), Avaliação psicológica: Aspectos teóricos e práticos (pp. 187-197). Petrópolis, RJ: Vozes.

Rafalski, J. C., \& Andrade, A. L. (2015). Prática e formação: Psicólogos na peritagem em porte de arma de fogo. Psicologia: Ciência e Profissão, 35(2), 599-612. http://dx.doi.org/10.1590/1982-370301472013

Ready, R. E., \& Veague, H. B. (2014). Training in psychological assessment: current practices of clinical psychology programs. Professional Psychology: Research and Practice, 45(4), 278-282. http://dx.doi.org/10.1037/a0037439

Resolução No 002, de 23 de março de 2003. Define e regulamenta o uso, a elaboração e a comercialização de testes psicológicos e revoga a Resolução CFP n 025/2001. Brasília, DF: Conselho Federal de Psicologia. Recuperado de http://site.cfp.org.br/wp-content/uploads/2003/03/resolucao2003_02_Anexo.pdf

Resolução No 002, de 21 de janeiro de 2016. Regulamenta a Avaliação Psicológica em Concurso Público e processos seletivos de natureza pública e privada e revoga a Resolução CFP No 001/2002. Brasília, DF: Conselho Federal de Psicologia. Recuperado de https://site.cfp.org.br/wp-content/uploads/2016/04/Resolução-002-2016.pdf

Resolução No 005, de 8 de março de 2012. Altera a Resolução CFP 002/2003, que define e regulamenta o uso, a elaboração e a comercialização de testes psicológicos. Brasília, DF: Conselho Federal de Psicologia.

Resolução No 006, de 17 de março de 2007. Institui o Código de Processamento Disciplinar. Brasília, DF: Conselho Federal de Psicologia. Recuperado de https://site.cfp.org.br/wp-content/uploads/2012/07/Resolução-CFP-no-006-07_timbrada-e-alterada.pdf

Resolução No 007, de 14 de junho de 2003. Institui o Manual de Elaboração de Documentos Escritos produzidos pelo psicólogo, decorrentes de avaliação psicológica e revoga a Resolução CFP 17/2002. Brasília, DF: Conselho Federal de Psicologia.

Resolução No 009, de 25 de abril de 2018. Estabelece diretrizes para a realização de Avaliação Psicológica no exercício profissional da psicóloga e do psicólogo, regulamenta o Sistema de Avaliação de Testes Psicológicos - SATEPSI e revoga as Resoluções $n^{\circ} 002 / 2003$, nº 006/2004 e n 005/2012 e Notas Técnicas nº 01/2017 e 02/2017. Brasília, DF: Conselho Federal de Psicologia. Recuperado de https://site.cfp.org.br/wp-content/uploads/2018/04/Resolução-CFP-no-09-2018-com-anexo.pdf

Resolução No 010, de 21 de julho de 2005. Aprova o Código de Ética Profissional do Psicólogo. Brasília, DF: Conselho Federal de Psicologia. Recuperado de http://site.cfp.org.br/wp-content/uploads/2012/07/codigo_etica.pdf

Resolução No 011, de 25 de junho de 2012. Regulamenta os serviços psicológicos realizados por meios tecnológicos de comunicação a distância, o atendimento psicoterapêutico em caráter experimental e revoga a Resolução CFP N. ${ }^{\circ}$ 12/2005. Brasília, DF: Conselho Federal de Psicologia.Diário Oficial da União. 25 jun. 2012.

Resolução $N^{o}$ 011, de 11 de maio de 2018. Regulamenta a prestação de serviços psicológicos realizados por meios de tecnologias da informação e da comunicação e revoga a Resolução CFP N.o 11/2012. Brasília, DF: Conselho Federal de Psicologia. Recuperado de https://site.cfp.org.br/wp-content/uploads/2018/05/RESOLUÇÃO-No -11-DE-11-DE-MAIO-DE-2018.pdf

Resolução $N^{\circ}$ 025, de 30 de novembro de 2001. Define teste psicológico como método de avaliação privativo do psicólogo e regulamenta sua elaboração, comercialização e uso. Brasília, DF: Conselho Federal de Psicologia. Recuperado de https://site.cfp.org.br/wp-content/uploads/2001/11/resolucao2001_25.pdf

Rodrigues, J. (2011). Considerações éticas na testagem. Revista de Psicologia, 2(1) 117-125.

Rouleau, C. R., Rash, J. A, \& Mothersill, K. J. (2016). Ethical issues in the psychosocial assessment of bariatric surgery candidates. Journal of Health Psychology, 21(7), 1457 1471. https://doi.org/10.1177/1359105314556160

Rueda, F. J. M., Noronha, A. P. P., Raad, A. J., \& Varandas, M. (2009). Cuestionario de competencia en evaluación psicológica: análisis de la estructura interna. Revista Interamericana de Psicología, 43(3), 618-626. 
Psicologia: Ciência e Profissão 2018 v. 38 (núm. esp.), 133-146.

Singer, P. (1998). Ética prática (2a ed.). São Paulo, SP: Martins Fontes.

Weschler, S. M. (2001). Princípios éticos e deontológicos na avaliação psicológica. In L. Pasquali (Org.), Técnicas de Exame Psicológico-TEP: manual (pp.171-193). São Paulo, SP: Casa do Psicólogo.

Zaia, P., Oliveira, K. S., \& Nakano, T. C. (2018). Análise dos processos éticos publicados no Jornal do Federal. Psicologia: Ciência e Profissão, 38(1), 8-21. https://doi.org/10.1590/1982-3703003532016

\section{Monalisa Muniz}

Doutora em Avaliação Psicológica e Docente da Universidade Federal de São Carlos. São Carlos - SP. Brasil.

E-mail: monamuniz@gmail.com

Endereço para envio de correspondência:

Departamento de Psicologia

Rodovia Washington Luís, km 235 - SP-310. CEP 13565-905.

São Carlos - São Paulo. Brasil.

Recebido 28/07/2018

Aprovado 08/08/2018

Received $07 / 28 / 2018$

Approved 08/08/2018

Recibido 28/07/2018

Aceptado 08/08/2018

Como citar: Muniz, M. (2018). Ética na Avaliação Psicológica: Velhas Questões, Novas Reflexões. Psicologia: Ciência e Profissão, 38(n.spe), 133-146. https://doi.org/10.1590/1982-3703000209682

How to cite: Muniz, M. (2018). Ethics in Psychological Assessment: Old Questions, New Reflections. Psicologia: Ciência e Profissão, 38(n.spe), 133-146. https://doi.org/10.1590/1982-3703000209682

Cómo citar: Muniz, M. (2018). Ética en la Evaluación Psicológica:Viejas Cuestiones, Nuevas Reflexiones. Psicologia: Ciência e Profissão, 38(n.spe), 133-146. https://doi.org/10.1590/1982-3703000209682 